\title{
Instantaneous and delayed responses of line intensities to interruption of the RF power in an argon inductively coupled plasma
}

Citation for published version (APA):

Fey, F. H. A. G., Stoffels, W. W., Mullen, van der, J. J. A. M., Sijde, van der, B., \& Schram, D. C. (1991). Instantaneous and delayed responses of line intensities to interruption of the RF power in an argon inductively coupled plasma. Spectrochimica Acta. Part B : Atomic Spectroscopy, 46(6-7), 885-900.

https://doi.org/10.1016/0584-8547(91)80088-K

DOI:

10.1016/0584-8547(91)80088-K

Document status and date:

Published: 01/01/1991

Document Version:

Publisher's PDF, also known as Version of Record (includes final page, issue and volume numbers)

Please check the document version of this publication:

- A submitted manuscript is the version of the article upon submission and before peer-review. There can be important differences between the submitted version and the official published version of record. People interested in the research are advised to contact the author for the final version of the publication, or visit the $\mathrm{DOI}$ to the publisher's website.

- The final author version and the galley proof are versions of the publication after peer review.

- The final published version features the final layout of the paper including the volume, issue and page numbers.

Link to publication

\footnotetext{
General rights

- You may freely distribute the URL identifying the publication in the public portal. follow below link for the End User Agreement:

www.tue.nl/taverne

\section{Take down policy}

If you believe that this document breaches copyright please contact us at:

openaccess@tue.nl

providing details and we will investigate your claim.
}

Copyright and moral rights for the publications made accessible in the public portal are retained by the authors and/or other copyright owners and it is a condition of accessing publications that users recognise and abide by the legal requirements associated with these rights.

- Users may download and print one copy of any publication from the public portal for the purpose of private study or research.

- You may not further distribute the material or use it for any profit-making activity or commercial gain

If the publication is distributed under the terms of Article 25fa of the Dutch Copyright Act, indicated by the "Taverne" license above, please 


\title{
Instantaneous and delayed responses of line intensities to interruption of the RF power in an argon inductively coupled plasma*
}

\author{
F. H. A. G. Fey, W. W. Stoffels, J. A. M. van der Mullen, $\dagger$ B. van der Sijde \\ and D. C. SCHRAM \\ Physics Department, Eindhoven University of Technology, P.O. Box 513, 5600 MB Eindhoven, \\ The Netherlands
}

(Received 26 November 1990; accepted 3 February 1991)

\begin{abstract}
Instantaneous and delayed responses of line intensities to the sudden interruption of the RF power have been studied in an argon inductively coupled plasma (ICP).

The instantaneous responses are caused by equilibrium shifts in the balances of elementary processes that control the populations of the excited states. It has been found that excited levels of Ar and $\mathrm{H}$ are predominantly populated by recombination of free electrons with ionic species, while most levels of metals such as $\mathrm{Mg}, \mathrm{Cd}, \mathrm{Na}, \mathrm{Fe}, \mathrm{Al}$ and $\mathrm{Cu}$ are populated by excitation from the ground state atom. Also charge transfer between $\mathrm{Mg}_{1}$ and $\mathrm{Ar}_{1}$ has been observed in the temporal behaviour of line intensities of two $\mathrm{Mg}^{+}$ states, quasi-resonant for charge transfer. Furthermore, we observed that in the inner part of the plasma the temperature remains constant during the recombination decay time, after an initial cooling of the electrons to the heavy particle temperature. When the power is switched on again, the electron temperature seems to increase temporarily to a value that is higher than the steady state value.

The delayed responses are caused by disturbances created in the expansion zone of the plasma during and after the interruption. It was found that these disturbances travel through the plasma with a velocity of $12 \mathrm{~m} \mathrm{~s}^{-1}$.
\end{abstract}

\section{INTRODUCTION}

We are pleased to be able to contribute to this special PaUl Boumans issue. As members of the Plasma and Atomic Physics Group of the University of the same city in which PAUL Boumans works, Eindhoven, we often had contacts with the group of Analytical and Inorganic Preparative Chemistry of Philips Research Laboratories. The fact that these contacts are pleasant and rewarding is largely due to inspiring interactions with Paul Boumans. We also take this opportunity to mention Dr Wil KNIPPENBerg who headed the Philips "Analytical Group" until April 1990. He had an important impact on the cooperation between the two groups.

In 1981, one of our students, Ivo RaAIJMAKERS, was invited to work with Paul at Philips Research Laboratories in the field of the inductively coupled plasma (ICP). At that time, the keyword in this field was "temperature". And this keyword was used very often with various adjectives. Thus there were translation temperatures, such as electron, ion and heavy particle temperature and temperatures describing ratios of intensities as ionization, excitation, rotational, and vibrational temperatures. Most popular was the 2 line or $2-\lambda$ temperature $T_{2 \lambda}$, which was easy to determine by comparing two relative intensities. However, it turned out that this quantity was ambiguous and very treacherous [1]. Almost any pair of lines introduced a $T_{2 \lambda}$ with an uncertainty of typically $20 \%$. Therefore, at that time the conclusion was that the ICP had to be far from LTE. On the other hand, there was suspicion, because the Griem criterion predicted that the plasma could not be far from LTE in this $n_{\mathrm{e}}$ range [2].

Partly due to the cooperation between the University of Eindhoven and the Philips Group this paradox has been solved. The answer was: abandon the $2-\lambda$ temperature as a thermodynamic property and replace the relative measurements by the absolute

\footnotetext{
* This article was published in the Special Boumans Festschrift Issue of Spectrochimica Acta.

† Author to whom correspondence should be addressed.
} 
measurement of one argon line [3]. The combination of the obtained excited state density with the ground state density (obtained from the pressure) gives the electron density $n_{\mathrm{e}}$ and a temperature close to $T_{\mathrm{e}}$. This procedure reduces the plasma indefiniteness drastically, and it has turned out that the main part is close to rather than far from LTE.

Other groups also started characterizing the plasma by $n_{\mathrm{e}}$ values. The work of CAUGHLIN and Blades in particular, based on spatially resolved measurements of $\mathrm{H}_{\beta}$ broadening $[4,5]$, gave good results. In our group, NowAK $[6,7]$ compared the $n_{\mathrm{e}}$ values obtained from absolute densities of excited Ar states with those of the spatially resolved $\mathrm{H}_{B}$ broadening technique. An essential role in this comparative study was played by the parameter $b_{1}=n(1) / n^{s}(1)$, which gives the departure of the argon ground state density $n(1)$ from its Saha equilibrium value $n^{\mathrm{s}}(1)$. The factor $b_{1}$ is very important, because, if $b_{1}$ and $n_{\mathrm{e}}$ are known, it is possible to calculate $T_{\mathrm{e}}$. The measurements of NowAK et al. gave global insight into the plasma characteristics. It has been found that the close-to-LTE concept holds in the bulk part of the ICP, whereas ionizing and recombining parts can be distinguished from each other. In an ionizing region of the plasma (e.g. the skin), where $b_{1}>1$, electrons are created since ionization exceeds recombination. These electrons will then be transported to recombining plasma parts, where $b_{1}<1$.

The close-to-LTE concept resolves the problems of the large uncertainty in the global plasma characterization, but it does not provide a method to explain in detail why the slope of the atomic state distribution function (ASDF) may vary from element to element. Nor does it provide an explanation for the matrix effects or the role of the easily ionizable elements. Therefore there is still a lot of work to be done, both experimentally and theoretically, in order to understand the importance of bulk transport (diffusion, convection), outward transport of particles (electrons and photons) and the various elementary processes (electron excitation, recombination, Penning ionization, charge transfer and excitation transfer) in the plasma. In order to understand why the population density of levels deviates from their LTE value, it is necessary to investigate how levels are populated and depopulated by different processes, which, in their turn, are controlled by elementary balances [8-11]. This question can be studied experimentally by disturbing the steady state of the plasma and observing the response of various levels. Based on the relaxation technique of GurEvich and PODMOSHENSKII [12], as applied to arcs $[13,14]$, one can disturb the plasma by rapidly changing the power delivered to the plasma. PARISI et al. $[15,16]$ and OLESIK and BRADLEY [17] modulated the RF power of the ICP sinusoidally and with a quasi rectangular wave. FARNSwORTH et al. $[18,19]$ switched off the generator completely during $200 \mu \mathrm{s}$. In these studies the main attention was focused on the effect of the transport of active species from the active to the passive zone by modulation or interruption. Therefore they mainly dealt with the spatially dependent delay of the arrival of a macroscopic disturbance, which we call the delayed response. The work of BYDDER and MILLER [20-23] was much more addressed to the instantaneous and local responses of excitation mechanisms to the interruption of the generator. From the responses of levels in partial local Saha equilibrium (pLSE) [9] the ratio of electron and heavy particle temperature $\gamma=T_{\mathrm{e}} / T_{\mathrm{h}}$ was determined in analogy with the technique described in [12]. In this way it was possible to determine the region where the energy is coupled into the plasma (where $\gamma>1$ ).

We expected that our $100 \mathrm{MHz}$ Philips ICP with the corresponding small skin depth would be very suitable for such an experiment. Therefore, we went to Philips with the request to make a pulse mode for the generator, which switches the generator off and on. Again it was the encouragement of Boumans and the support of KNIPPENBERG that made an experiment with very special features possible. Essential are the short power interruptions (20-100 $\mu \mathrm{s})$, the high duty cycle of the measuring system (almost $100 \%$ ) and the optimum repetition frequency of the interruptions $(40 \mathrm{~Hz})$.

Striking differences are found between the instantaneous responses of the various atomic lines (cf. Section 4). This is related to the fact that the production-destruction balance is level dependent. We can distinguish between the responses of balances of 
the Saha (S), Boltzmann (B), charge transfer (CT) and excitation transfer (ET) types, which will be defined in the next section of this paper. Also delayed responses in line intensities have been observed. They seem to result from the arrival of perturbations, created in the expansion zone of the plasma below the coil. These results have proved that the interruption experiment gives a vast amount of information and it is to be expected that much more results can be obtained using this technique.

\section{THEORY}

In order to understand how the interruption of the generator power influences the ASDF of the species in the plasma, one should be aware that the disturbance of the energy balance occurs essentially stepwise. There is a chain of links through which the energy flows. The RF generator heats the electrons $\{\mathrm{e}\}$ which deliver energy to the heavy particles $\{h\}$. These, in their turn, are cooled by the surroundings. Schematically the energy balance is presented by:

$$
\mathrm{RF} \rightarrow\{\mathrm{e}\} \rightarrow\{\mathrm{h}\} \rightarrow \text { surroundings. }
$$

A sudden interruption of the RF power, as performed in a pulsation experiment, creates effects on several time scales because the various processes have different time constants.

(A) Interrupting the generator gives the following sequence of so called instantaneous events.

(1) Cooling: immediately after switching off the power supply, the first link RF $\rightarrow$ $\{\mathrm{e}\}$ disappears, and, owing to the second chain $\{\mathrm{e}\} \rightarrow\{\mathrm{h}\}$, the electron temperature changes from $T_{\mathrm{e}}$ to $T_{\mathrm{e}}^{*}=T_{\mathrm{h}}$ within a time $\tau_{\mathrm{\epsilon}} \simeq 1 \mu \mathrm{s}$ (cf. [20, 24]).

(2) Recombination: the electrons recombine "slowly" with a time constant $\tau_{n}\left(\simeq 10^{-4}\right.$ to $10^{-3} \mathrm{~s}$ (cf. [20])).

(3) Heating: immediately after the power is switched on, the opposite of cooling takes places with $\tau \simeq \tau_{\epsilon}$, restoring $T_{\mathrm{e}}>T_{\mathrm{h}}$.

(4) Ionization: a "slow" increase of $n_{\mathrm{e}}$ with $\tau \simeq \tau_{n}$ towards the steady-state value.

(B) Furthermore, the temporary interruption of the energy supply to the plasma causes a macroscopic disturbance in the expansion zone below the coil. This disturbance travels through the plasma and is observed in higher regions as a delayed event.

(5) The perturbation arrival: a wave package of typically $\tau_{\mathrm{w}}=5 \mathrm{~ms}$ is observed. The time of arrival depends on the spatial position of the observed plasma part.

All events will cause responses of the plasma emission. Below we will confine ourselves to the responses of line emission to the instantaneous events (1)-(4). The propagation of the disturbance (5) will be discussed in Section 4.3. The study of instantaneous events gives insight into local microscopic processes on the following conditions.

(i)The plasma should be in a steady state at the start of the power interruption. This means that mixing of the instantaneous events (1-4) and the delayed event (5) of the previous interruption must be avoided. This puts an upper limit to the repetition frequency of the power interruption for which we found $40 \mathrm{~Hz}$.

(ii)The off period $\Delta t$ should be smaller than the characteristic transport time, the time needed to transport essential different plasma parts to the observation location.

In formula: $v \Delta t<<L$; where $v$ is the bulk velocity and $L$ the gradient length of the plasma, the characteristic length in which the change of plasma conditions is moderate.

For the interpretation of instantaneous responses of line intensities we distinguish four production-destruction balances governing the population of excited states. These balances, the Saha balance, the Boltzmann balance, the excitation transfer balance, and the charge transfer balance, are treated below. (For a detailed treatment, see [8-11]). 
(I) The electron controlled Saha balance (S) of ionization and recombination, i

$$
X_{p}+e+\left(I_{p}\right) \leftarrow \mathrm{S} \rightarrow X_{1}^{+}+e+e,
$$

where $X_{p}$ refers to excited state $p$ of particle $X, X_{1}^{+}$to the corresponding ion ground state, and $I_{p}$ to the ionization energy of state $p$; thus, $I_{p}$ is the difference between the ionization energy of the atom and the excitation energy of the state, both taken with respect to the ground level. Clearly this balance is controlled by electrons and therefore $T_{\mathrm{e}}$ dependent.

For highly excited states, where Saha processes are expected to be dominant, the Saha balance equilibrates. Those levels are said to be in partial local Saha equilibrium ( $\mathrm{pLSE}$ ). The number density of state $\mathrm{p}$ in $\mathrm{pLSE}$ is given by

$$
\eta^{\mathrm{S}}(p) \equiv \eta_{+}(1) n_{\mathrm{e}} / 2\left[\mathrm{~h}^{3} /\left(2 \pi m_{\mathrm{e}} k T_{\mathrm{e}}\right)^{3 / 2}\right] \exp \left(I_{p} / k T_{\mathrm{e}}\right) \text {. }
$$

where $\eta=n / g$, with $n(p)$ being the level density and $g(p)$ the number of states of level $p$, and $\eta_{+}(1)$ the number density of the ion ground state.

(II) The electron controlled Boltzmann balance (B) of excitation from and deexcitation to the ground state,

$$
X_{p}+\mathrm{e} \leftarrow \mathrm{B} \rightarrow X_{1}+e+\left(E_{p}\right),
$$

where $X_{1}$ is the atom ground state and $E_{p}$ the excitation energy of state $p$. Just like the Saha balance, the Boltzmann balance is controlled by electrons, and is consequently $T_{\mathrm{e}}$ dependent.

In the case of local Boltzmann equilibrium, the density of a state $p$ will be

$$
\eta^{\mathrm{B}}(p) \equiv \eta(1) \exp \left(-E_{p} / k T_{\mathrm{e}}\right),
$$

in which $\eta(1)$ is the number density of the ground state. Note that the effect of a change in $T_{\mathrm{e}}$ on the population of a state governed by the Boltzmann balance will be opposite to the effect on a state in pLSE. Apart from the sign of the argument of the exponent in Eqns (2) and (4) this also follows from the fact that the energies $\left(I_{p}\right)$ and $\left(E_{p}\right)$ in Eqns (1) and (3) occupy opposite places with respect to $X_{p}$.

(III) The balance between charge transfer (CT) of an ion state of one element to the ground state of another element, and vice versa, is given by:

$$
X_{1}+Y_{\mathrm{r}}^{+} \leftarrow \mathrm{CT} \rightarrow X_{\mathrm{q}}^{+}+Y_{1},
$$

where $Y_{\mathrm{r}}^{+}$and $X_{\mathrm{q}}^{+}$are states resonant for charge transfer. When CT is dominant for a state $Y_{r}^{+}$, its density will be:

$$
\eta^{\mathrm{CT}}\left(Y_{\mathrm{r}}^{+}\right)=\frac{\eta\left(Y_{1}\right)}{\eta\left(X_{1}\right)} \eta^{\mathrm{CT}}\left(X_{\mathrm{q}}^{+}\right)
$$

(IV) The balance between excitation transfer (ET) of an excited state of one element to the ground state of another element and the corresponding backward process:

$$
X_{\mathrm{r}}+Y_{1} \leftarrow \mathrm{ET} \rightarrow X_{1}+Y_{\mathrm{q}}
$$

The density of an excited state $X_{\mathrm{r}}$, for which the ET balance is dominant, is, similar to the CT case, given by:

$$
\eta^{\mathrm{ET}}\left(X_{\mathrm{r}}\right)=\frac{\eta\left(X_{1}\right)}{\eta\left(Y_{1}\right)} \eta^{\mathrm{ET}}\left(Y_{\mathrm{q}}\right)
$$

The balances CT and ET describe heavy particle processes, not involving free electrons. In contrast to the $T_{\mathrm{e}}$ dependent population controlled by $\mathrm{S}$ or $\mathrm{B}$, the population of states resonant for ET or CT is temperature independent (Eqns 6 and 8), as there are no changes in kinetic energy in the forward and backward processes.

All balances interact with each other. In the fictitious case of LTE, this leads to an equilibrium where the relations (2), (4), (6) and (8) between the state densities hold 
simultaneously. In a non LTE situation, however, equilibrium departure of one balance will disturb the other balances as well. For example, the overpopulation of lower $\mathrm{Ar}$ levels in an ionizing $\mathrm{Ar} / \mathrm{Mg}$ mixture (a departure from LTE), will affect the ASDF of $\mathrm{Mg}$ through the CT balance.

It is the charm of the power interruption technique that the investigation of the responses of various levels gives insight into the state and hierarchy of the balances in the undisturbed plasma.

Since the elementary balances consist of fast processes with relaxation times smaller than $10^{-8} \mathrm{~s}$, we assume that they equilibrate continuously during the relaxation of the electron temperature $\left(\tau_{\epsilon} \simeq 10^{-6} \mathrm{~s}\right)$ and density $\left(\tau_{\mathrm{n}} \simeq 10^{-4}-10^{-3} \mathrm{~s}\right)$. From Eqns (1), (2) and (3), (4) it fôllows that the response to a change in electron temperature (at cooling and heating) of a state controlled by the Saha balance differs from the response of a state which is governed by the Boltzmann balance. Let $\gamma$ be the ratio of the initial electron temperature $T_{\mathrm{e}}$ to the final electron temperature $T_{\mathrm{e}}^{*}$, then, the responses of a Saha state and a Boltzmann dominated state will be $[24,25]$ :

$$
\begin{array}{ll}
\ln \frac{\eta^{\mathrm{S}}(\mathrm{p})^{*}}{\eta^{\mathrm{S}}(\mathrm{p})}=\frac{\gamma-1}{k T_{\mathrm{e}}} I_{p}+\frac{3}{2} \ln \gamma, & \text { Saha } \\
\ln \frac{\eta^{\mathrm{B}}(p)^{*}}{\eta^{\mathrm{B}}(p)}=-\frac{\gamma-1}{k T_{\mathrm{e}}} E_{p}, & \text { Boltzmann }
\end{array}
$$

where $\eta(p)$ denotes the density at the initial $T_{\mathrm{e}}$ and $\eta(p)^{*}$ the density at the final $T_{\mathrm{e}}^{*}$. It is assumed that $n_{\mathrm{a}}, n_{\mathrm{e}}$ and $n_{+}$are constant during $\tau_{\epsilon}$, since $\tau_{\epsilon}<<\tau_{\mathrm{n}}$. These different responses can be used to investigate whether a state is populated by the Boltzmann or the Saha balance.

In general situations more than one balance will control the population of a state, so that the response to changes of the electron temperature will be a combination of the balances involved. Therefore we shall use the expressions "Saha-like" and "Boltzmann-like" behaviour.

\section{EXPERIMENTAL}

For the experiments an RF generator developed by Philips operating at $100 \mathrm{MHz}$ was used. The RF-coil consists of two windings with a diameter of $35 \mathrm{~mm}$ and a height of $15 \mathrm{~mm}$. The plasma torch consists of three concentric quartz tubes and is a standard torch developed by Philips [26]; the outlet of the intermediate tube is placed $5 \mathrm{~mm}$ below the coil. The argon flows during standard conditions are $12 \mathrm{l} / \mathrm{min}$ outer flow, $0 \mathrm{l} / \mathrm{min}$ intermediate flow and $0.7 \mathrm{l} / \mathrm{min}$ inner flow and the power input is $0.8 \mathrm{~kW}$. Introduction of analyte is done by nebulizing an aqueous solution with the inner flow using a cross-flow nebulizer. Under standard conditions the solution flow rate is $1.4 \mathrm{ml} / \mathrm{h}$.

The basic experimental setup is shown in Fig. 1. The switching of the generator is performed by providing a pulse circuit inside the generator with block pulses at TTL level. The off period of the generator can be varied from 20 to $100 \mu \mathrm{s}$. The timing diagram of the measurement is

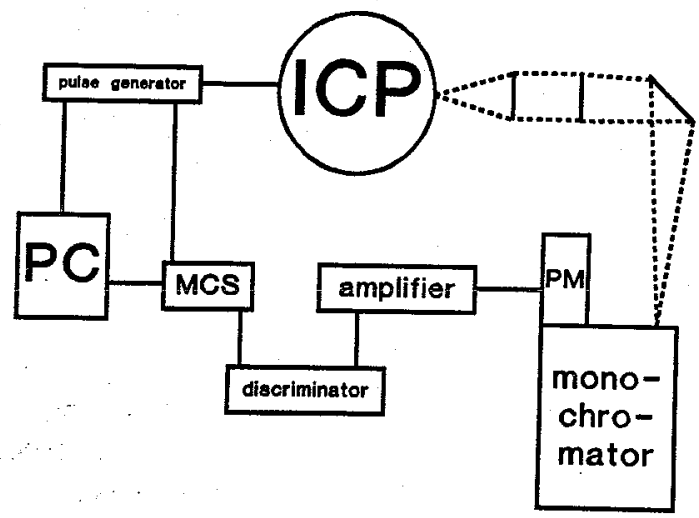

Fig. 1. Basic experimental setup. PM: photomultiplier; MCS: multi channel scaler. 
shown in Fig. 2. Using a pick-up coil, we measured the decay time of the EM field (to $10 \%$ of the stationary value) to be $3 \mu \mathrm{s}$, while the rise time (to $90 \%$ of the stationary value) was found to be $1.5 \mu \mathrm{s}$, upon switching off and on, respectively.

The plasma is focused (1:0.78 image) on the entrance slit of a 1-m B\&M BM100 monochromator with a 1200 grooves/mm grating. The detector is an EMI $9698 \mathrm{QB}$ photomultiplier, operated at a voltage of $1400 \mathrm{~V}$. After being amplified 50 times by a Philips variable gain amplifier (model 777), which has a rise time of $1.8 \mathrm{~ns}$, the anode signal is discriminated by a Philips discriminator (model 715). The pulses from the discriminator can be counted as a function of time by an EG\&G Ortec ACE-MCS Multi Channel Scaler (MCS), which has 4096 counters of 24 bits. By using this MCS we can observe about $8 \mathrm{~ms}$ continuously with a total resolution of $2 \mu \mathrm{s}$; this value is dictated by the minimum counting resolution of the MCS.

A photon count rate $5-10 \%$ higher during periods in which the generator is on, compared to periods in which the generator power is interrupted, is induced by EM field disturbances. Recent improvements have reduced the effect of this influence to $0.5 \%$.

\section{RESULTS}

\subsection{Response times}

For getting general information about the time-dependent behaviour of the plasma and the quality of our experimental method, we present the temporal behaviour of the $\operatorname{Ar}(6 d-4 p)$ transition line at $549.59 \mathrm{~nm}$, for which the plasma is assumed to be optically thin. The plasma was operated at standard conditions with water injection and the lateral measurement was taken $3 \mathrm{~mm}$ above the load coil (ALC) and $6 \mathrm{~mm}$ from the centre. Figure 3a shows the response during the first $400 \mu \mathrm{s}$; the upward jump at $t=0 \mu \mathrm{s}$, due to electron cooling (1, cf. Section 2), and the downward jump at $75 \mu \mathrm{s}$, due to electron heating (3), take about $8 \mu \mathrm{s}$. So the time resolution of the MCS $(2 \mu s)$ is sufficient. The upward jump at cooling and the downward jump at heating are typical for a level in pLSE (Eqn 9). This instantaneous Saha like response of the $6 d$ level justifies the conclusion that the Saha balance is important for this level.

Figures $3 \mathrm{~b}$ and $3 \mathrm{c}$ show the response during $5 \mathrm{~ms}$ and $80 \mathrm{~ms}$, respectively. After about $1.8 \mathrm{~ms}$, a package of disturbances with a width of about $4 \mathrm{~ms}$ arrives at this

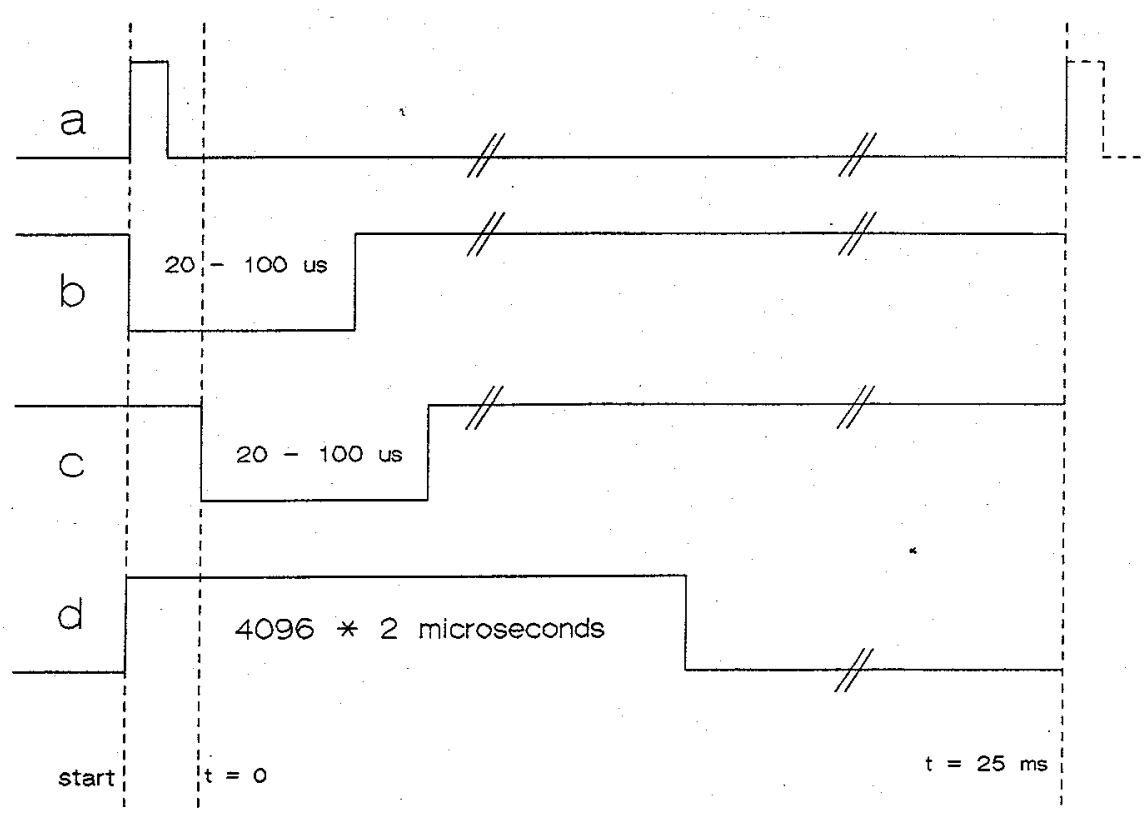

Fig. 2. Timing diagram. (a) Start pulse of the computer; this triggers (b) the pulse generator, which (c) causes the temporary power interruption the RF generator after a delay of $30 \mu \mathrm{s}$ and (d) triggers the MCS which starts counting during $4096 \times 2 \mu$ s. This cycle is generally repeated about 4000 times (number of repetitions) with a repetition frequency of $40 \mathrm{~Hz}$. 


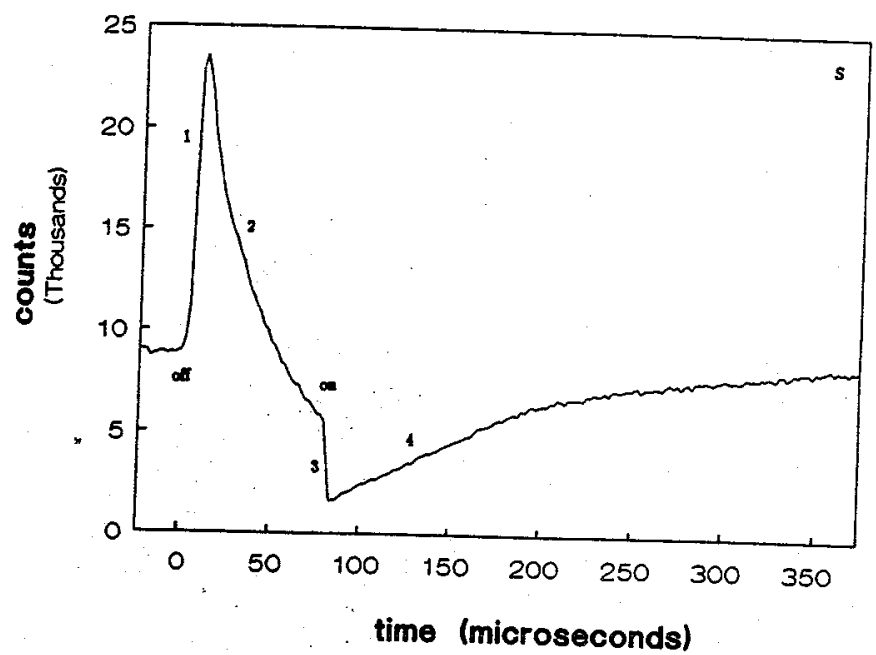

(a)

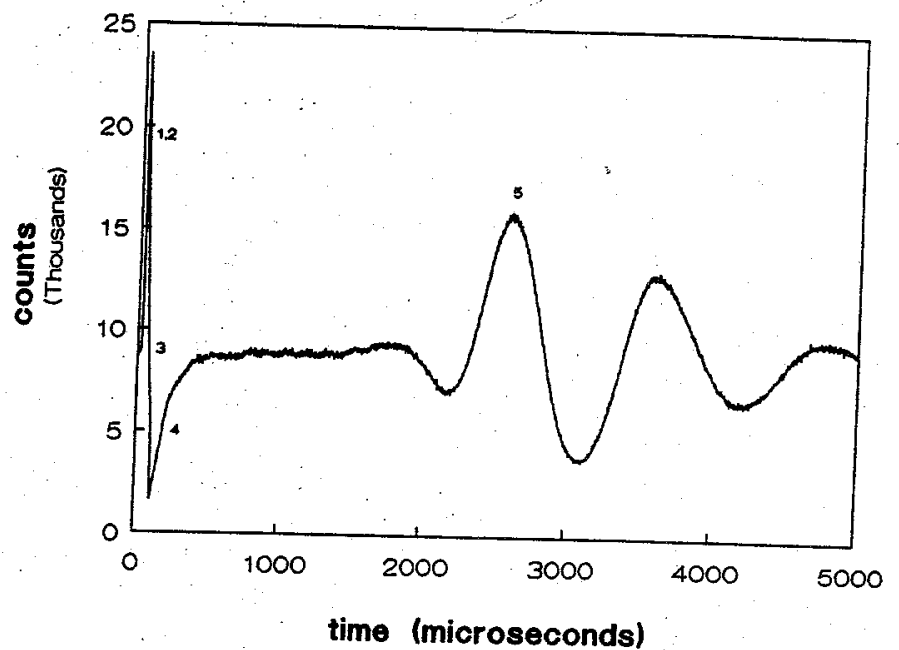

(b)

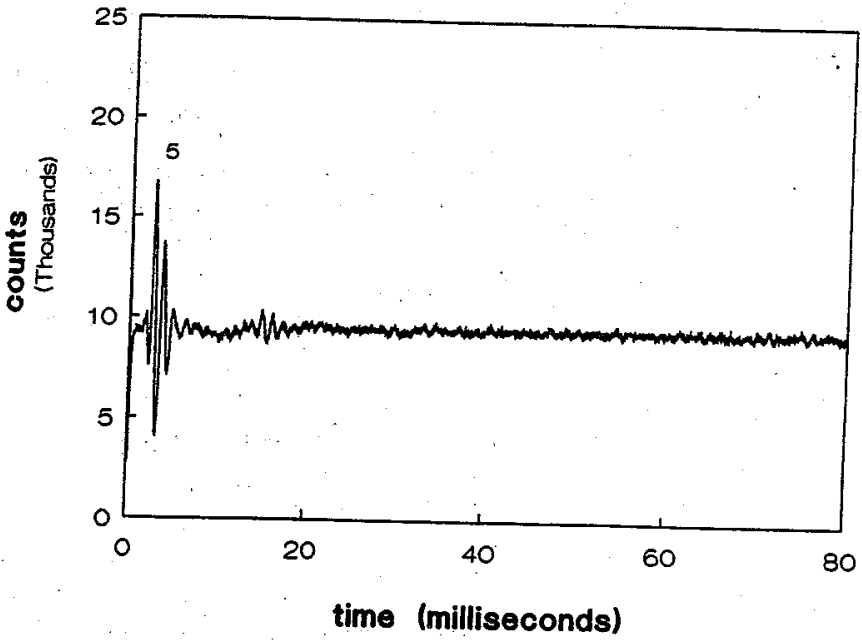

(c)

Fig. 3. Response of the $\operatorname{Ar}(6 d)$ level at $3 \mathrm{~mm} \mathrm{ALC}$ and $r=6 \mathrm{~mm}$ over (a) $400 \mu \mathrm{s}$, (b) $5000 \mu \mathrm{s}$ and (c) $80 \mathrm{~ms}$. Visible are the Saha-like response to instantaneous events, electron cooling (1) followed by decay due to recombination (2) and the electron heating (3) followed by ionization (4). Delayed effects (5) occur after $1.8 \mathrm{~ms}$. After $20 \mathrm{~ms}$, the system returns to a steady state. Outer flow: $12 \mathrm{l} / \mathrm{min}$, inner flow: $0.7 \mathrm{l} / \mathrm{min}$ with aerosol injection, input power: $0.8 \mathrm{~kW}$. Number of repetitions: 5000 (a), (b), 500 (c); time per channel: $2 \mu \mathrm{s}$ (a), (b), $20 \mu \mathrm{s}$ (c); repetition frequency: $40 \mathrm{~Hz}$ (a), (b), $9 \mathrm{~Hz}$ (c). 
plasma location. A second one with the same time structure, but with lower amplitude, arrives after $20 \mathrm{~ms}$. These delayed events labelled with (5) in Figure $3 \mathrm{~b}$ are of a completely different nature than the instantaneous events labelled (1-4). In Section 4.3 these delayed events will be further discussed. From this measurement we can conclude that there will be nowhere an overlap from different pulsing periods provided that the repetition frequency of the interruption is less than $43 \mathrm{~Hz}$. To avoid interference of the instantaneous responses with the arrival of the first ringing of the previous interruption, it is safe to use a repetition frequency of $100 \mathrm{~Hz}$. Interference with the arrival of the second ringing will cause only minor effects. For future measurements with high accuracy we will use a repetition frequency of $40 \mathrm{~Hz}$, being much higher than the $0.5 \mathrm{~Hz}$ used in $[22,23]$. When much higher frequencies are used to pulse or modulate the energy input, like $1 \mathrm{kHz}$ modulation, the overlap of the disturbances will become so large that a straightforward interpretation will be impossible.

\subsection{Measurements on instantaneous processes}

4.2.1. Response of Ar. In Fig. 3a we have shown the Saha like response of $\operatorname{Ar}(6 d)$, which is typical for all Ar levels investigated. To investigate whether the Saha balance completely dominates these levels we followed the procedure given in $[12,24]$. We have measured the "cooling jump" for several lines and have plotted the results as a function of the ionization energy (Fig. 4). The measurement has been performed at $5 \mathrm{~mm}$ above the load coil and $4 \mathrm{~mm}$ from the centre. We observe that the levels with an ionization potential less than $0.7 \mathrm{eV}$ (which is comparable to $T \mathrm{e}$ ) are all on a straight line and therefore expected to be close to Saha equilibrium before and after cooling. The jumps of lower levels are further away from this line, which means that there is a departure from pLSE before and/or after the cooling.

If we assume Saha equilibrium and calculate (Eqn 9) $\gamma, T_{\mathrm{e}}$ and $T_{\mathrm{h}}$ from the cooling jumps of the levels with $I_{p}<0.7 \mathrm{eV}$, we find $\gamma=1.35, T_{\mathrm{e}}=0.65 \mathrm{eV}$ and $T_{\mathrm{h}}=0.48$ $\mathrm{eV}$. The value for the electron temperature is in agreement with those obtained by other techniques [6] and [27]. However, this method is sensitive to small deviations from equilibrium. The value of $\gamma$ is reliable and can be easily determined within 5 per cent. The obtained value is in agreement with that reported by MrLLER [23].

Figure 5 gives the relative response of several Ar levels as functions of time. It shows that the time constant of the decay of the line intensity, defined as the time in which the intensity decreases by a factor $e$, is level independent. This value is $85 \mu \mathrm{s}$. This implies that, at this plasma location, the slope of the ASDF remains constant

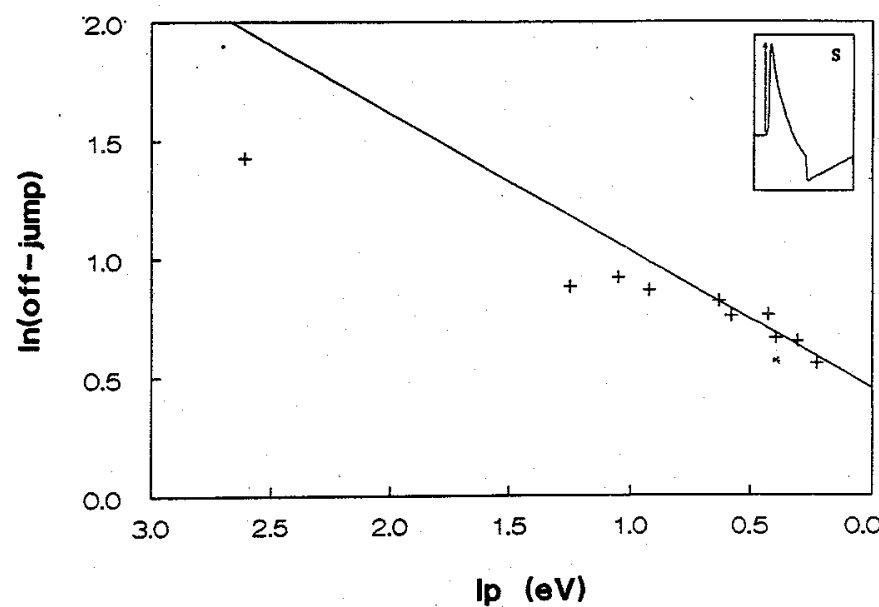

Fig. 4. Relative cooling jump of argon levels as a function of the ionization energy of the excited states at $5 \mathrm{~mm}$ ALC and $r=4 \mathrm{~mm}$. The least squares fitting for levels in pLSE $\left(I_{p}<0.7 \mathrm{eV}\right)$ gives $T_{\mathrm{c}}=0.65 \mathrm{eV}, T_{\mathrm{h}}=0.48 \mathrm{eV}$. Coolant flow: $12 \mathrm{l} / \mathrm{min}$, inner flow: $1.0 \mathrm{l} / \mathrm{min}$ with aerosol injection; power input: $0.8 \mathrm{~kW}$. Number of repetitions: 4000 ; time per channel: $2 \mu \mathrm{s}$; repetition frequency; $100 \mathrm{~Hz}$. 


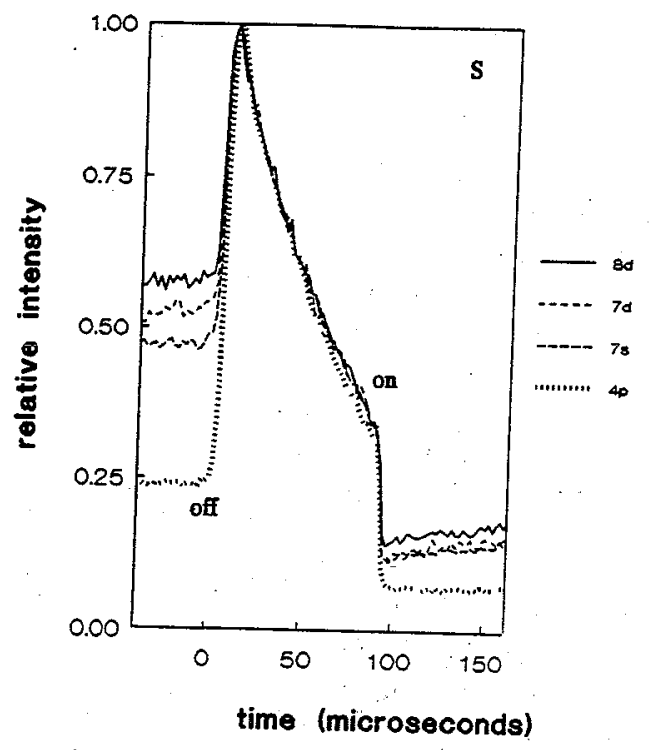

Fig. 5. Relative response of several argon levels at $5 \mathrm{~mm} \mathrm{ALC}$ and $r=4 \mathrm{~mm}$ over $200 \mu \mathrm{s}$. Note that the decay of the lines is synchronous, so that the slope of the ASDF is constant, indicating a constant $T_{\mathrm{h}}$. Outer flow: $12 \mathrm{l} / \mathrm{min}$, inner flow: $1.0 \mathrm{l} / \mathrm{min}$ with aerosol injection; power input: $0.8 \mathrm{~kW}$. Number of repetitions: 4000 ; time per channel: $2 \mu \mathrm{s}$; repetition frequency; $100 \mathrm{~Hz}$.

during recombination and that the electron temperature $\left(T_{\mathrm{e}}^{*}=T_{\mathrm{h}}\right)$ does not change substantially. Since the Saha density scales with $n_{e} n_{\mathrm{Ar}^{+}}=n_{\mathrm{e}}^{2}$, we may use these results to determine the electron recombination time $\tau_{\mathrm{n}}$. It is found that $\tau_{\mathrm{n}}=170 \mu \mathrm{s}$. This is
in agreement with the value given in [19].

Figure 6 shows the decay of various levels at an outer part of the plasma, namely at $3 \mathrm{~mm}$ ALC and $r=6 \mathrm{~mm}$. It is clear that in this outward region the slope of the ASDF is not constant during the recombination. Apparently the electron temperature decreases during the off-period, which might be due to the large temperature gradients

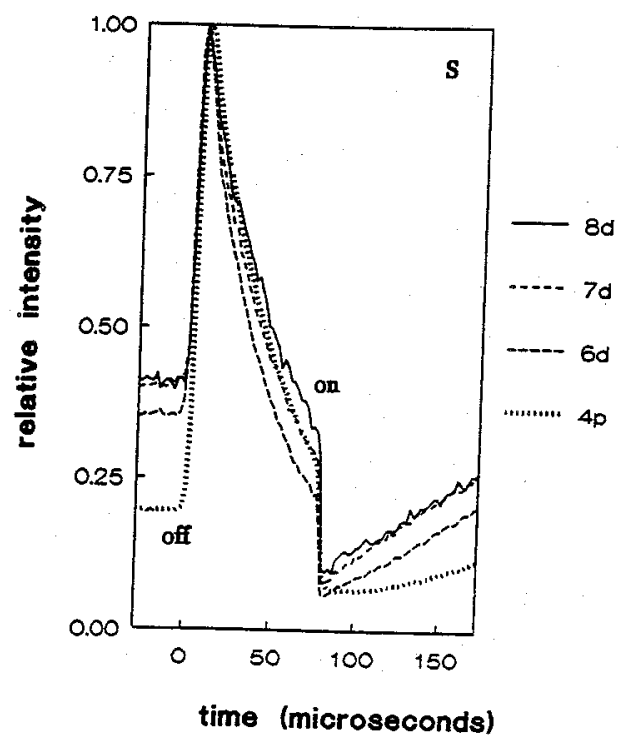

Fig. 6. Relative response of several argon levels at $3 \mathrm{~mm} \mathrm{ALC}$ and $r=6 \mathrm{~mm}$ over $200 \mu \mathrm{s}$ Note that the decay of lines during recombination is not synchronous, so that the slope of the ASDF decreases and therefore $T_{\mathrm{h}}$ as well. Outer flow: $12 \mathrm{l} / \mathrm{min}$, inner flow: $0.7 \mathrm{l} / \mathrm{min}$ with aerosol injection, power input; $0.8 \mathrm{~kW}$. Number of repetitions: 5000 ; time per channel: $2 \mu \mathrm{s}$; repetition frequency; $40 \mathrm{~Hz}$. 
associated with a large outward energy flow. Now we return to the position of $5 \mathrm{~mm}$ ALC and $r=4 \mathrm{~mm}$ to study the heating jump when the generator is switched on. This differs from the cooling jump, since in this case the electron temperature increases from the heavy particle temperature to a higher temperature. The dependence of the heating jump on the ionization energy is shown in Fig. 7. Although the dependence is less clear than in the case of the cooling jump, we may conclude (Eqn 9) that $T_{\mathrm{e}} / T_{\mathrm{h}}$ $\simeq 1.6$ is larger at the heating jump than at the cooling jump.

Taking into account that the heavy particle temperature did not change significantly during the process, we may conclude that the electron temperature just after the switching on is higher than under steady state conditions.

4.2.2. Response of hydrogen. The response of hydrogen, which is due to the introduction of water into the plasma, has been investigated as well. It appears that, just as in the argon case, the response of $\mathrm{H}$ is Saha-like. This follows from Fig. 8, which gives the response of the fifth level of $\mathrm{H}$ at $5 \mathrm{~mm}$ ALC and $r=4 \mathrm{~mm}$. The

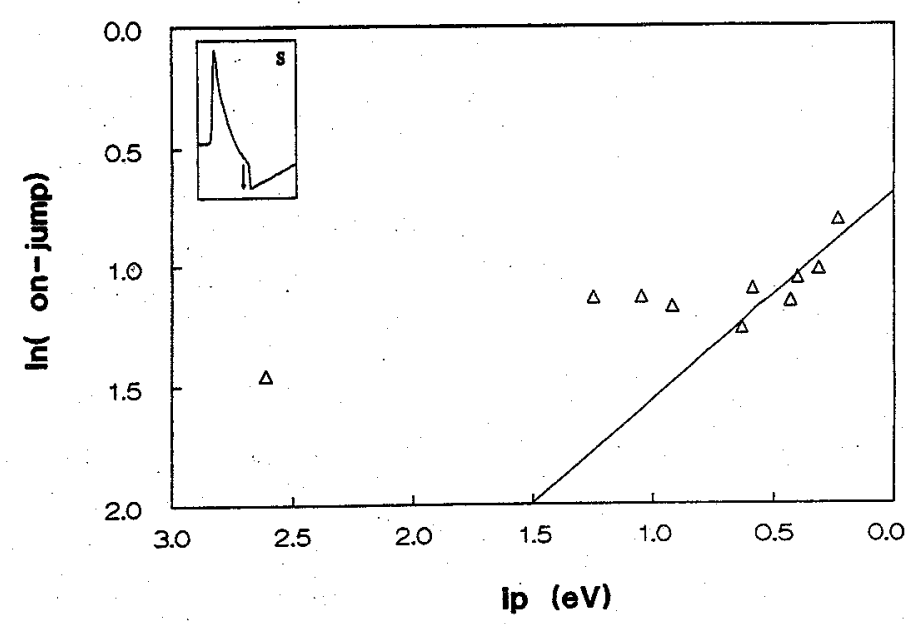

Fig. 7. Relative heating jump of argon levels as a function of the ionization energy at $5 \mathrm{~mm}$ ALC and $r=4 \mathrm{~mm}$. Note that the jumps of states with $I_{p}<0.7 \mathrm{eV}$ are on one line, indicating pLSE. Outer flow: $12 \mathrm{l} / \mathrm{min}$, central flow: $1.0 \mathrm{l} / \mathrm{min}$ with aerosol injection; power input; $0.8 \mathrm{~kW}$.

Number of repetitions; 4000 ; time per channel: $2 \mu$ s; repetition frequency; $100 \mathrm{~Hz}$.

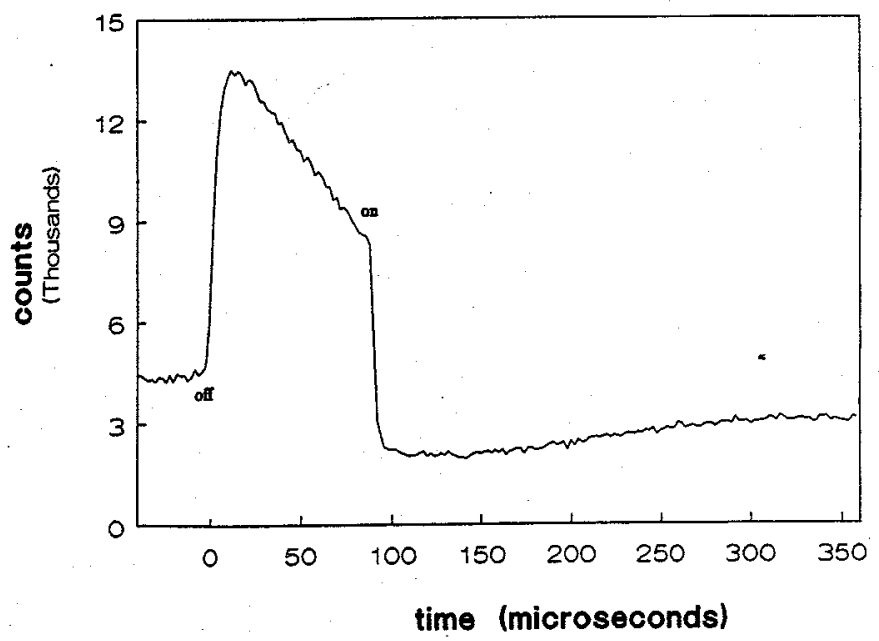

Fig. 8. Instantaneous response in intensity of the fifth level of $\mathrm{H}$ at $5 \mathrm{~mm} \mathrm{ALC}$ and $r=4 \mathrm{~mm}$ over $400 \mu \mathrm{s}$. The response is Saha dominated and has a decay time of $180 \mu \mathrm{s}$. Outer flow; $12 \mathrm{l} / \mathrm{min}$, inner fow: $1.0 \mathrm{l} / \mathrm{min}$ with aerosol injection; power input; $0.8 \mathrm{~kW}$. Number of repetitions: 4000 ; time per channel: $2 \mu s$; repetition frequency; $100 \mathrm{~Hz}$. 
decay time of the line intensity $(180 \mu \mathrm{s})$, however, is much larger than that of Ar. Apparently the $\mathrm{H}^{+}$concentration decreases far more slowly than that of $\mathrm{Ar}^{+}$.

Furthermore, we have measured the cooling jumps of some $\mathrm{H}$ levels (Fig. 9). It appears that the cooling jumps of $H$ levels are larger than those of Ar levels with the same ionization energy. Especially the fifth level, $H(5)$, deviates. An explanation of this effect might be the fact that the excitation energy of $\mathrm{H}(5)$ is almost the same as that of $\operatorname{Ar}(4 p)$ (cf. Fig. 9), so that excitation transfer is possible and this means that the ET balance

$$
\operatorname{Ar}(1)+\mathrm{H}(5) \leftarrow \mathrm{ET} \rightarrow \mathrm{Ar}(4 p)+\mathrm{H}(1)
$$

can be important. In the fictitious case of total dominance of this ET balance, the cooling jumps of $\mathrm{H}(5)$ and $\operatorname{Ar}(4 p)$ will be exactly the same (Eqn 8), (compare to Fig. 9).

4.2.3. Response of metals. Metals respond in a way completely different from that of $\mathrm{Ar}$ and $\mathrm{H}$. This can be explained by the relatively small excitation energy of the first excited state. Figure 10 shows the response of $\mathrm{Mg}$ I $(3 p 3 s)$, the first excited level in the $\mathrm{Mg}$ I system, at $5 \mathrm{~mm}$ ALC and $r=3 \mathrm{~mm}$. A similar response is observed for the lowest excited states of $\mathrm{Na}, \mathrm{Ca}, \mathrm{Cu}, \mathrm{Al}, \mathrm{Cd}$ and $\mathrm{Fe}$ in their atomic and ionic systems. We see a downward intensity jump during cooling (event 1), a constant intensity during recombination (2) and large upward jump at heating (3), followed by an approach to the steady state value (4).

This behaviour can be explained by assuming that the $\mathrm{Mg}$ level is dominated by the Boltzmann balance of excitation from and de-excitation to the ground state atom. In such a case we might expect a downward jump due to the cooling of the electrons (event 1) and a large upward jump due to heating of electrons to an intensity that is even higher than the steady state situation, provided that the electron temperature is also higher than the stationary electron temperature (cf. Eqn 10). This had already been observed in Ar (cf. Fig. 7).

We measured the behaviour of some lines of $\mathrm{Mg} \mathrm{I}$ and $\mathrm{Mg}$ II to investigate the balances of the various levels. We observe (Fig. 11) that the cooling jump decreases for higher excited levels, although it might be expected from Eqn (10) that the downward jump should increase in the case of total dominance of the Boltzmann balance. However, it is likely that the influence of the Saha balance on the population of highly excited levels increases, approaching the continuum of the $\mathrm{Mg}$ I system. This

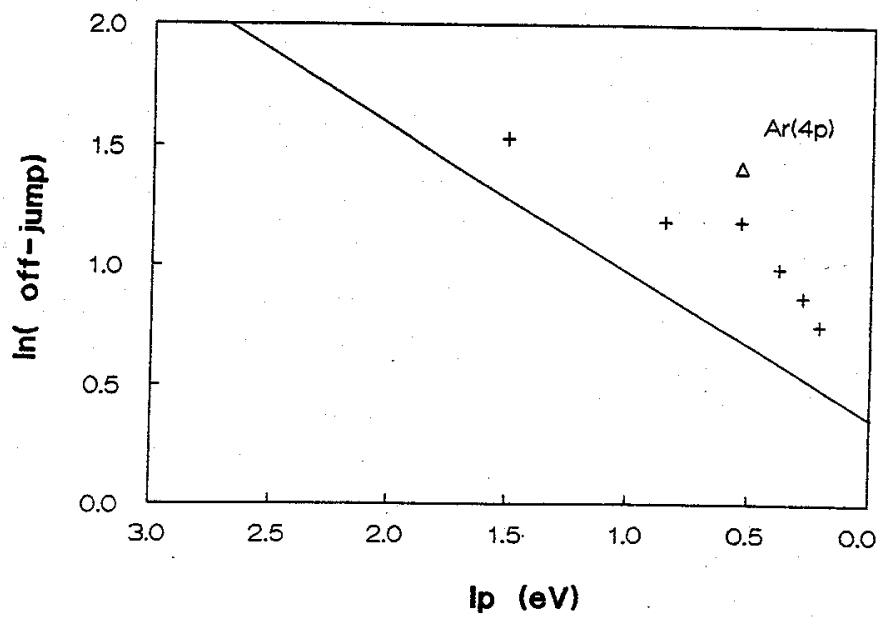

Fig. 9. Relative cooling jump of hydrogen levels as a function of the ionization energy at $5 \mathrm{~mm}$ ALC and $r=5 \mathrm{~mm}$. The jump of $\operatorname{Ar}(4 p)$ is indicated at its excitation energy. The line indicates the fitted height of the Ar jumps shown in Fig. 4. Outer flow; $121 / \mathrm{min}$, inner flow; $1.0 \mathrm{l} / \mathrm{min}$ with aerosol injection; power input: $0.8 \mathrm{~kW}$. Number of repetitions: 4000 ; time per channel: $2 \mu \mathrm{s}$; repetition frequency $100 \mathrm{~Hz}$. 


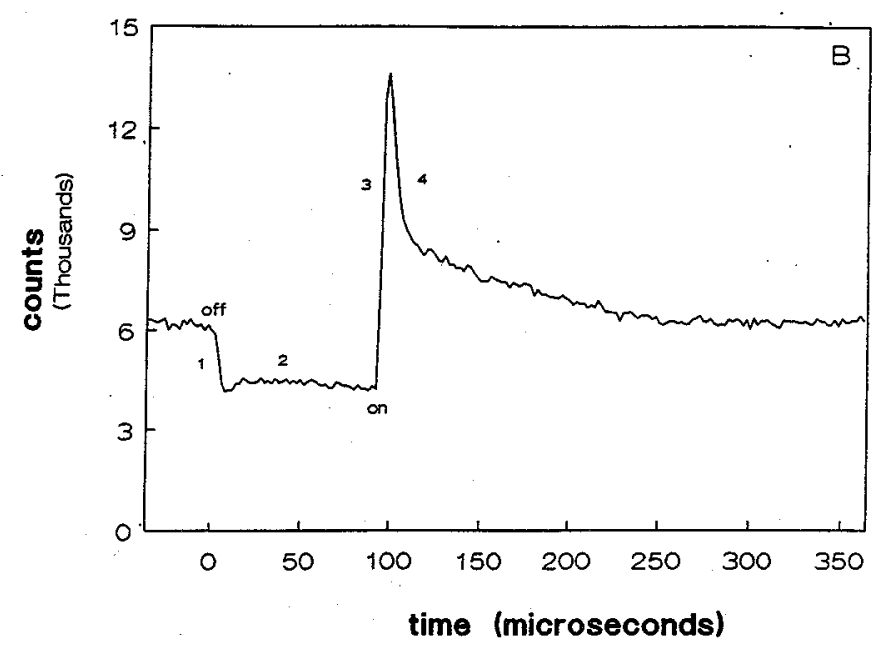

Fig. 10. Response of the $\mathrm{Mg} \mathrm{I}(3 p 3 s)$ level at $5 \mathrm{~mm} \mathrm{ALC}$ and $r=3 \mathrm{~mm}$ over $400 \mu \mathrm{s}$. Note that Boltzmann dominated instantaneous response of a downward jump at cooling, constant intensity during recombination and upward jump at heating. Outer flow: $12 \mathrm{l} / \mathrm{min}$, central flow: $1.0 \mathrm{l} / \mathrm{min}$ with aerosol injection, $[\mathrm{Mg}]=1 \mathrm{~g} / \mathrm{l}$; power input; $0.8 \mathrm{~kW}$. Number of repetitions: 4000; time per channel: $2 \mu$ s; repetition frequency; $100 \mathrm{~Hz}$.

might explain the experimental results. The reactions of $\mathrm{Mg}^{+}(3 p)$ and $\mathrm{Mg}^{+}(4 f)$ can be explained in the same way as a response to the combination of the Boltzmann balance to the ground state of $\mathrm{Mg}^{+}$and the Saha balance of ionization to and recombination of $\mathrm{Mg}^{2+}$. However, two levels of $\mathrm{Mg}^{+}$respond in a totally different way (cf. Fig. 11) [28]. The lack of a rapid cooling response indicates that these levels are not controlled by electron induced balances, at least not at the switching off. Since these levels lie about $16 \mathrm{eV}$ above the $\mathrm{Mg}_{1}$ level, this might indicate that we are confronted with a manifestation of the CT balance, in this particular case given by

$$
\operatorname{Ar}(1)+\mathrm{Mg}_{\mathrm{r}}^{+} \leftarrow \mathrm{CT} \rightarrow \mathrm{Ar}^{+}(1)+\mathrm{Mg}(1) .
$$

The small peak at switching on must be caused by a Boltzmann like balance.

\subsection{Macroscopic disturbances :}

As has been shown in Fig. 3b and 3c, there are changes in line intensities that occur much later after the power interruption than the instantaneous responses. These disturbances, which we call delayed responses, can be reproduced with an accuracy of $5 \mu \mathrm{s}$ and are easily observed in the whole plasma, except for the regions below the coil. Since the time duration between these delayed responses and the instantaneous responses is longer the higher the observation position, we must conclude that these disturbances are travelling through the plasma.

The shape of the delayed disturbances for levels ruled by the Saha balance turns out to be independent of the level. Levels dominated by the Boltzmann balance respond in globally the same way, but the amplitude of the disturbances is much smaller than in the case of the Saha levels. Also the continuum behaves similarly. Figure 12 shows that the times of arrival of two extremes in line intensity at a certain height above the coil at $r=4 \mathrm{~mm}$ vary linearly with the height. From these measurements it follows that the speed is smaller in the lower part of the plasma between the windings of the coil. Above the coil, the axial velocity of the highest peak is $12.1 \mathrm{~m} \mathrm{~s}^{-1}$ whereas the velocity of the second peak equals $11.7 \mathrm{~m} \mathrm{~s}^{-1}$. Extrapolation to the period of the interruption gives a position below the radiating plasma. Therefore, the place of creation of the disturbance is probably the expansion zone of the plasma. The measured velocities are of the same order as the expected drift velocity of the plasma. 


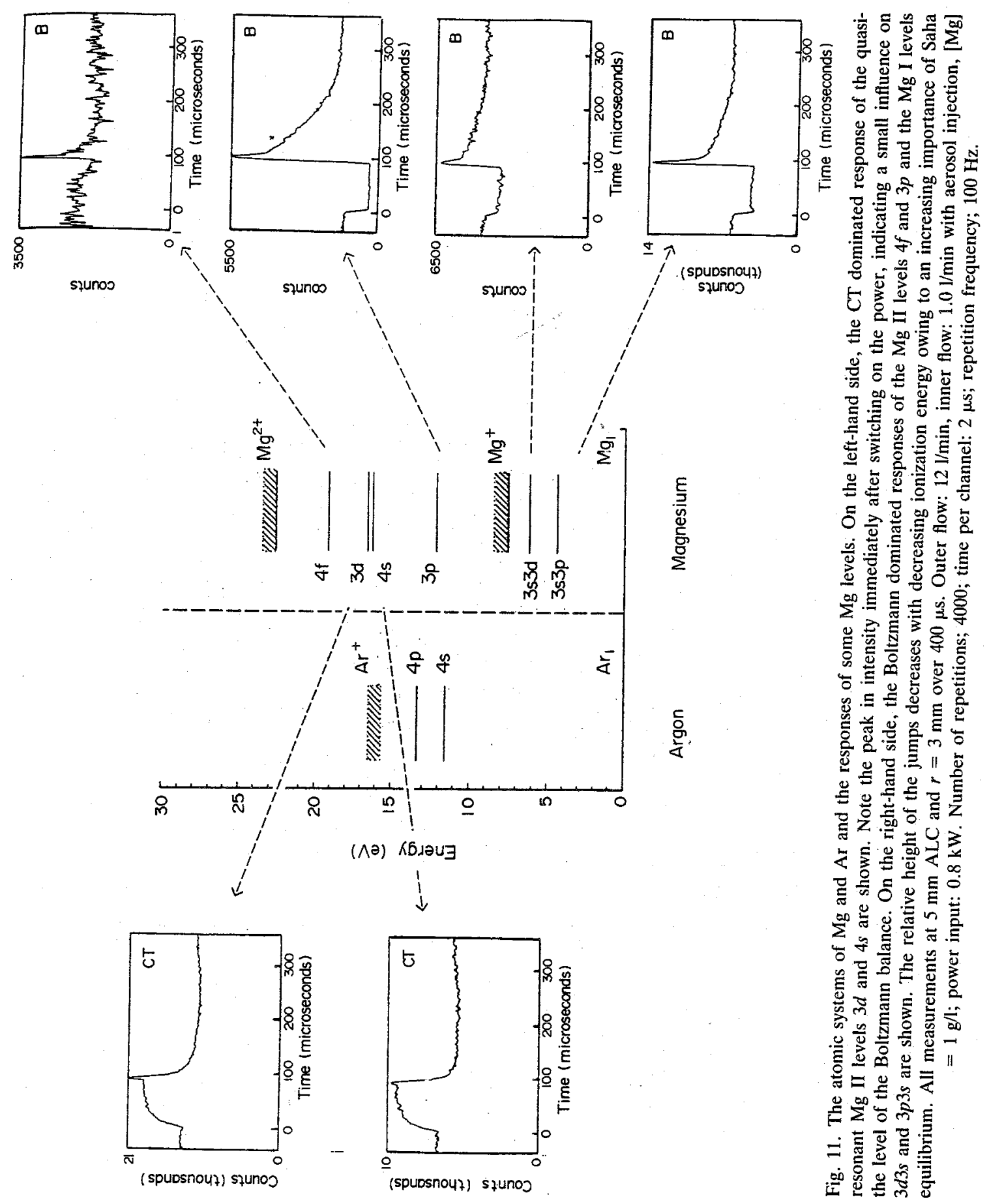




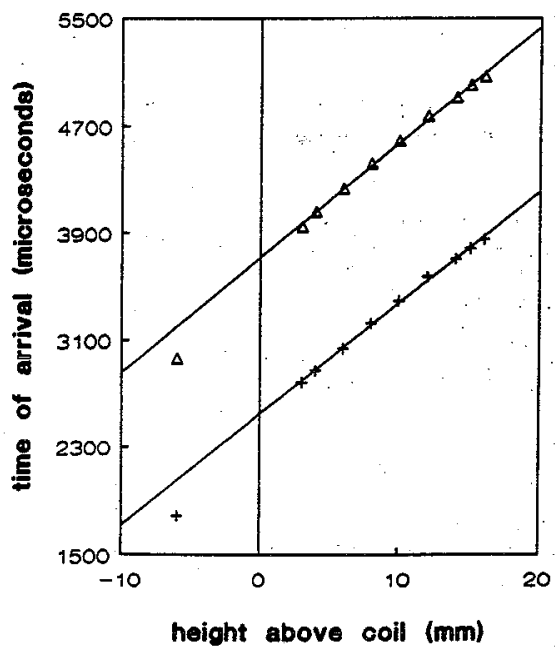

Fig. 12. Time of arrival of the first (lower line) and second (upper line) peak of the first package of the macroscopic disturbances as a function of the height above the load coil at $r$ $=4 \mathrm{~mm}$. Velocities, calculated by least squares fitting, give (first peak) $v=12.1 \mathrm{~m} / \mathrm{s}$ and (second peak) $v=11.7 \mathrm{~m} / \mathrm{s}$. Outer flow: $12 \mathrm{1} / \mathrm{min}$, inner flow; $0.7 \mathrm{l} / \mathrm{min}$ with aerosol injection; power input: $0.8 \mathrm{~kW}$. Number of repetitions: 5000 ; time per channel: $2 \mu \mathrm{s}$; repetition frequency; $40 \mathrm{~Hz}$.

The off-period and the ratio of the highest peak to the stationary level of the $\operatorname{Ar}(6 d)$ line show (Fig. 13) an almost linear dependence with an offset in time of $8 \mu \mathrm{s}$. Note that this offset is the same as the electron cooling time.

\section{Conclusions}

The response of line intensities to the interruption of the plasma power appears to have a dual character. Initially, we observe an instantaneous local response caused by the changes in the balances controlling the population of the states. These changes are

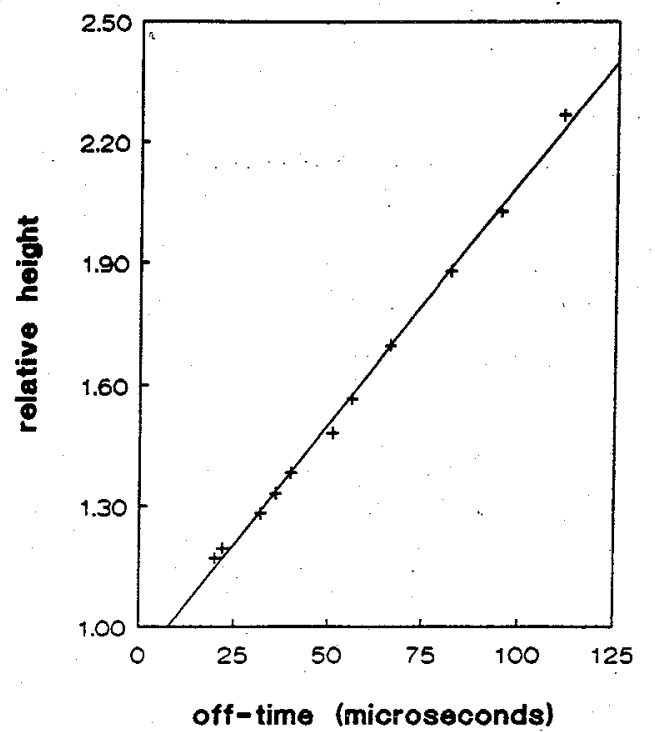

Fig. 13. Relative height (ratio of the highest peak to the stationary level) of the first package of disturbances as a function of the off-period at $r=4 \mathrm{~mm}$. Note the offset in time of $8 \mu \mathrm{s}$. Outer flow: $12 \mathrm{l} / \mathrm{min}$, inner flow: $0.7 \mathrm{l} / \mathrm{min}$ with aerosol injection, power input: $0.8 \mathrm{~kW}$. Number of repetitions: 5000; time per channel: $2 \mu$ s; repetition frequency; $40 \mathrm{~Hz}$. 
affected by the four events: cooling, recombination, heating and ionization. Secondly, we observe a delayed response which can be interpreted as the arrival of disturbances created in the expansion zone of the plasma, travelling with an axial velocity of about $12 \mathrm{~m} \mathrm{~s}^{-1}$.

The investigation of Ar levels in the skin showed that the population of these levels is largely dominated by the Saha balance. From the response to cooling, it can be deduced that during steady-state conditions $\gamma=T_{\mathrm{e}} / T_{\mathrm{h}} \simeq 1.35$. The highest levels are found to be in Saha equilibrium during the steady state and the interruption period. During the off-period, when the recombination decay time of $\mathrm{Ar}_{1}^{+}$with electrons is $170 \mu \mathrm{s}$, it is found that the temperature remains unchanged (and $T_{\mathrm{e}}^{*}=T_{\mathrm{h}}$ ). When the power is switched on, the electron temperature is temporarily significantly higher than under steady state conditions. Hydrogen responds Saha-like, similarly to argon, but the levels are also influenced by another process, possibly excitation transfer. It has been observed that $\mathrm{H}^{+}$recombines much slower than $\mathrm{Ar}_{1}^{+}$during the off-period of the generator.

The instantaneous responses of excited states of metals such as $\mathrm{Mg}, \mathrm{Na}, \mathrm{Ca}, \mathrm{Cu}$, $\mathrm{Fe}, \mathrm{Cd}$ and $\mathrm{Al}$ are generally Boltzmann-like. A response of the charge transfer type has been found for excited $\mathrm{Mg}^{+}$levels that are resonant for CT with $\mathrm{Ar}_{1}^{+}$.

These results have proved that the use of a multi-channel scaler is a powerful tool for performing time dependent photon counting measurements of line intensities on a $\mu s$ time scale. The method allows the measurements of intensities with an accuracy in time of $2 \mu \mathrm{s}$ and an error in intensity of $1 \%$, so that very small changes in line intensities can be observed.

Acknowledgements-These investigations in the program of the Foundation for Fundamental Research on Matter (FOM) have been supported by the Netherlands Technology Foundation (STW).

We would like to thank Ir. G. A. A. Asselman, CFT Philips Eindhoven for providing us with an ICP equipment. We are especially indebted to Dr W. F. KNIPPENBERG, Philips Research Laboratories Eindhoven, who enabled us to do the pulsation experiments.

\section{REFERENCES}

[1] B. van der Sijde and J. A. M. van der Mullen, J. Quant. Spectrosc. Radiat. Transfer 44, 39 (1990).

[2] H. Griem, Phys Rev. 13, 1170 (1963).

[3] I. J. M. M. Raaijmakers, P. W. J. M. Boumans, B. van der Sijde and D. C. Schram, Spectrochim. Acta 38B, 697 (1983).

[4] B. L. Caughlin and M. W. Blades, Spectrochim. Acta 39B, 1583 (1984).

[5] B. L. Caughlin and M. W. Blades, Spectrochim. Acta 40B, 987 (1985).

[6] J. A. M. van der Mullen, S. Nowak, A. C. A. P. van Lammeren, D. C. Schram and B. van der Sijde, Spectrochim. Acta 43B, 317 (1988).

[7] S. Nowak, J. A. M. van der Mullen, and D. C. Schram, Spectrochim. Acta 43B, 1235 (1988).

[8] J. A. M. van der Mullen, Spectrochim. Acta 44B, 1067 (1989).

[9] J. A. M. van der Mullen, Spectrochim. Acta 45B, 1 (1990).

[10] J. A. M. van der Mullen and D. C. Schram, Spectrochim. Acta 45B, 233 (1990).

[11] J. A. M. van der Mullen, Phys. Rep. 191, 109 (1990).

[12] D. B. Gurevich and I. V. Podmoshenskii, Opt. Spectrosc. 15, 319 (1963).

[13] H. Kafrouni, J. M. Bagneux, A. Gleizes and S. Vacquie, J. Quant. Spectrosc: Radiat. Transfer 21, 457 (1979).

[14] K.-P. Nick, J. Richter and V. Helbig, J. Quant. Spectrosc. Radiat. Transfer 32, 1 (1984).

[15] A. F. Parisi, G. D. Rayson and G. M. Hieftje, Spectrochim. Acta 42B, 361 (1987).

[16] A. F. Parisi, G. M. Hieftje, Appl. Spectrosc. 40, 181 (1986).

[17] J. W. Olesik and K. R. Bradley, Spectrochim. Acta 42B, 377 (1987).

[18] P. B. Farnsworth, Appl. Spectrosc. 39, 1078 (1985).

[19] P. B. Farnsworth, D. A. Rodham and D. W. Ririe, Spectrochim. Acta 42B, 393 (1987).

[20] E. L. Bydder and G. P. Miller, Spectrochim. Acta 43B, 819 (1988).

[21] E. L. Bydder and G. P. Miller, Spectrochim. Acta 43B, 1431 (1988).

[22] E. L. Bydder and G. P. Miller, Spectrochim. Acta 44B, 165 (1989).

[23] G. P. Miller, Spectrochim. Acta 44B, 395 (1989).

[24] G. P. Miller, Spectrochim. Acta 45B, 329 (1990).

[25] J. A. M. van de Mullen, W. W. Stoffels, F. H. A. G. Fey and D. C. Schram, 8th Symposium on Elementary Processes and Chemical Reactions in Low Temperature Plasma, Stará Lesná, High Tatras, Czechoslovakia (1990) 
[26] P. W. J. M. Boumans and M. Ch. Lux-Steiner, Spectrochim. Acta 37B, 97 (1982).

[27] M. Huang and G. M. Hieftje, Spectrochim. Acta 44B, 291 (1989).

[28] J. A. M. van der Mullen, I. J. M. M. Raaijmakers, A. C. A. P. van Lammeren, D. C. Schram, B. van der Sijde and H. J. W. Schenkelaars, Spectrochim. Acta 42B, 1039 (1987). 